\title{
Instructional Activities on Calculus for High School Level by Using a TI Nspire CX CAS Graphing Calculator
}

\author{
Sayun Sotaro*, Sermsri Thaithae, Pisuttawan Sripirom Sirininlakul \\ Department of Mathematics, Faculty of Sciences Srinakharinwirot University \\ Bangkok, Thailand \\ *say@g.swu.ac.th
}

\begin{abstract}
The purposes of this study were 1) to study the achievement and the efficiency of instructional activities on calculus for high school level by using a TI Nspire CX CAS graphing calculator and 2) to study students' satisfaction toward workshop learning with instructional activities on calculus for high school level. The samples of this study were 16 students of the second and third-year who were studying Bachelor of Science and Bachelor of Education (Mathematics) in semester 3/2017, Mathematics Department, Faculty of Sciences, Srinakharinwirot University. The result of the study indicated that students had educational efficiency to pass the criteria more than 60 percent of the total students with a statistical significance level of .05 . The effectiveness (efficiency of process $\left(E_{1}\right) /$ efficiency of product $\left(E_{2}\right)$ ) of the instructional activities on calculus for high school level by using a TI Nspire CX CAS graphing calculator equal to 87.65/78.23. The students' satisfaction toward instructional activities on calculus for high school level by using a TI Nspire CX CAS graphing calculator was at a high level.
\end{abstract}

Keywords-instructional activities, calculus, graphing calculator, TI Nspire CX CAS

\section{INTRODUCTION}

Technological advancements in computers and calculators have played an important role in human functioning. This enables humans to perform tasks quickly and unlimitedly by the calculators that play a significant role in Thai mathematics teaching which is graphing calculators [1]. Graphing calculators play a role in teaching and solving various mathematical problems, which helps saving time in classes such as algebra and conversion geometry etc. It's easier to convey knowledge and thinking processes. Teachers can used to organize a variety of teaching styles, giving learners a sense of freedom to create conceptual ideas and help to quickly calculate complex patterns. Graphing calculators are useful tools for teaching mathematics at all levels including to help solve problems and to develop conceptual skills. Another important aspect is that learners can use graphing calculators to help create knowledge, new ideas, and also help learners to learn faster and easier.
The Texas Instruments model Nspire CX CAS Graphing Calculator, briefly called TI Nspire CX CAS, is the latest Computer Algebra System (CAS) graphing calculator of Texas Instruments. The characteristics of this hardware were 1) Graphing Calculator, 2) the convenience of data transferable, 3) rechargeable Battery, 4) English letter plastic keyboard, 5) color screen, $320 \times 240$ pixels, 6) 100 MB memory for recording and another $64 \mathrm{MB}$ for the operating system, 7) calculate and yield both real number and complex number, 8) algebra, calculus, and matrices can calculation by computer algebra system (CAS), 9) geometric program, 10) function graph, a graph of sequence, 3 dimensions graph, 11) find values from the chart: highest, lowest, integral, slope, intersection, contact line equation, 12) the statistics graph includes histograms, box plot graphs, dot graphs, line graphs, and regression equations. 13) matrices calculation, includes inverse, determinant, transpose and row operation, 14) calculate the logarithm, trigonometry, 15) can fit images into the calculator, etc.

Calculus is an extremely important subject that forms the basis of understanding nature and real-life phenomena. It can be applied to natural rules. It is also the basis of almost every field of science and is the necessary basis for modern science. As such, learning calculus is fixed to be learned for high school, and undergraduate level for almost every major. Normally, teaching calculus is a lecture base and emphasizes practice which enables students with a high ability to succeed in studying. For students with moderate and mild ability, they must try to put more time and effort into studying. The calculus teaching development guidelines should allow students to learn on their own. There should have media to practice according to the learning abilities of each learner. The instructor is responsible for guiding the learning path, suggesting the importance and benefits of the learning, and can be applied knowledge [2]. The study of Beth [3], observed and interviewed mathematics teachers who used graphing calculator to teach calculus, finding that graphing calculators are very useful in teaching mathematics, such as graphing calculators, making it easier and faster to calculate difficult calculations. Students can use graphing calculators to check the 
graph that they create accurately. Graphing calculators also help students to convert subjective visual to objective visual. However, students need to have an understanding of the rules, formulas, or theories they learn to use graphing calculators more efficiently. Ng Wee Leng [4] studied the use of graphing calculators and calculus. It aims to determine whether the use of TI Nspire can enhance teaching and calculus learning. The results showed that TI Nspire graphing calculators are an integral tool for teaching and learning calculus concepts in the classroom. It was also found that the use of graphing calculators was appropriate for the concept of algebra calculus. Students enable better visualization of concepts and make snapshots of relevant mathematical features. Also, students can associate and show the results on the same screen, especially algebra and graphics. The researchers were involved in the development of mathematical and statistical instructional activities including matrices [5], statistics in high school [6], statistics for research [7], linear programming [8], relations and functions [9], conic sections [10], and pre-calculus [11] respectively by using TI Nspire CX CAS graphing calculator and to study the satisfaction of teaching, which results in a high level of satisfaction in teaching activities.

Based on research studied in Thailand and foreign countries. It was found that the results of the instructional activities using graphing calculator help students to create subjective visual. It enabled students to observe, create knowledge that will link to objective visual. The Graphing calculator also helps to solve mathematical problems that enable teaching to be more effective. Students have fun learning environment. Therefore, based on the mention reasons, the researchers agreed that research should be done to create instructional activities using a TI Nspire CX CAS graphing calculator in calculus for high school level to enhance students' experience in the use of graphing calculator technology for instructional activities on calculus for high school level.

\section{RESEARCH OBJECTIVES}

- To create and study the achievements of instructional activities on calculus for high school level by using a TI Nspire CX CAS graphing calculator.

- To study the effectiveness of instructional activities on calculus for high school level by using a TI Nspire CX CAS graphing calculator according to criteria 75/75

- To study the student's satisfaction in the workshop of instructional activities on calculus for high school level by using a TI Nspire CX CAS graphing calculator.

\section{SCOPE OF RESEARCH}

\section{A. The Population Used in Research}

The population used in this study were 16 students of undergraduate students who were studying Bachelor of Science and Bachelor of Education (Mathematics). Department of Mathematics, Faculty of Sciences, Srinakharinwirot University.

The samples used in this study were 16 students of the second and third-year students who were studying Bachelor of Sciences and Bachelor of Education (Mathematics) in semester 3/2017, Department of Mathematics, Faculty of Sciences, Srinakharinwirot University.

\section{B. Limitation}

A primary limitation in the current research was the small sample size due to the intensive care required for the students thoroughly during the workshop and the limited number of TI Nspire CX CAS graphing calculators which were supported by Department of Mathematics, Faculty of Sciences, Srinakharinwirot University. The total number of 20 samples may lower the generalizability of results. The second limitation concerns the selective content of calculus which covered only 15 topics according to the course syllabus. However, the present study should be considered exploratory first step in examining the achievement and efficiency of instructional activities on calculus for high school level.

\section{Variables}

Independent variables were instructional activities on calculus for the high school level by using a TI Nspire CX CAS graphing calculator.

Dependent variables were activity performance, students' achievements, and satisfaction of students toward instructional activities on calculus for high school level by using a TI Nspire CX CAS graphing calculator.

\section{Research Tools}

- Instructional activities on calculus for high school level by using a TI Nspire CX CAS graphing calculator consists of 15 research topics : 1) Limit of functions 2) Limit theorem 3) Function continuity 4) Average change rate 5) Derivatives of functions 6) Formulas for finding function derivatives 7) Higher derivatives 8) Implicit differentiation 9) Slope of a curve or tangent lines 10) Speed and acceleration 11) Increasing and decreasing functions 12) Stationary points 13) Maximum and minimum problems 14) Indefinite and definite integrals 15) Area under a curve and area between two curves.

- The test measured the achievement of instructional activities on calculus for high school level by using a TI Nspire CX CAS graphing calculator.

- Student satisfaction questionnaire on instructional activities on calculus for high school level by using a TI Nspire CX CAS graphing calculator.

- TI Nspire CX CAS Graphing Calculator. 


\section{ReSEARCH Methodology}

\section{A. Creating and verifying the quality of the tool.}

- Instructional activities on calculus for high school level by using a TI Nspire CX CAS graphing calculator, took 2 days, 7 hours per day, divided into 15 topics.

- The test to measure the achievement of instructional activities on calculus for high school level by using a TI Nspire CX CAS graphing calculator, a subjective test for 6 items, with two experts to validate the criteria of Item Objective Congruence (IOC) guidelines to determine the consistency between the content of the test and the objective of behavioral learning, as well as suggestions on questions. Use subjective criteria with difficulty level between $0.20-0.80$ and classification power of 0.20 or higher, and the results of the analysis of the confidence test using Cronbach's ( $\alpha$-coefficient) which equal to 0.610 .

- The satisfaction questionnaire on instructional activities on calculus for high school level by using a TI Nspire CX CAS graphing calculator. Researchers developed the questionnaire based on the assessment of the workshop program of the Department of Mathematics, Faculty of sciences for 10 questions. The structure of the questionnaire was 5 points Likert scale: $5=$ the highest, $4=$ high, $3=$ moderate, $2=$ low, and $1=$ the lowest. The interpretation of the total average score, which resulted from the satisfaction of the sample students toward instructional activities on calculus for high school level by using a TI Nspire CX CAS graphing calculator. Based on the assessment criteria of [12]: an average score of $4.50-5.00$, means that the students were satisfied at the highest level. The average score of $3.50-4.49$ means that the students were satisfied at a high level. The average score of $2.50-$ 3.49 , means students were moderately satisfied. The average score of $1.50-2.49$ means students had low satisfaction, and an average score of $1.00-1.49$ means students had the least satisfaction. The result of the analysis of the confidence of the instructional activities on calculus for high school level by using a TI Nspire CX CAS graphing calculator using the Cronbach's $(\alpha-$ Coefficient) formula was 0.906 .

\section{B. Data Collection}

The researchers conducted a workshop of instructional activities on calculus for high school level by using a TI Nspire CX CAS graphing calculator for the sample students by own self for 2 days, 7 hours a day, and collected scores from activities during the workshop and scores from the achievement test to calculate a statistical value.

\section{RESEARCH RESULTS}

The researchers presented the results of the analysis as follows:
- Percentage, arithmetic, and standard deviations of academic ability of the sample students are shown in Table 1. According to table 1 , the scores that students got during learning activities, the achievement test, and achievement of instructional activities on calculus for high school level by using a TI Nspire CX CAS graphing calculator has the average arithmetic 35.06, 46.94 and 82.00 marks, respectively, representing 87.66 78.23 and 82.00, respectively, and the standard deviation was 5.23, 6.11 and 9.09 marks, respectively. Instructional activities on calculus for high school level by using a TI Nspire CX CAS graphing calculator had performance value equal to $87.66 / 78.23$ which was effective according to criteria $75 / 75$ that was set.

TABLE I. MEAN, PERCENTAGE, AND STANDARD DEVIATION OF SAMPLE STUDENT'S ACADEMIC ABILITY

\begin{tabular}{|l|l|l|l|l|c|}
\hline \multicolumn{1}{|c|}{ Score } & $\begin{array}{c}\text { Number of } \\
\text { students }\end{array}$ & $\begin{array}{c}\text { Total } \\
\text { score }\end{array}$ & Mean & Percentage & S.D. \\
\hline $\begin{array}{l}\text { During } \\
\text { Learning } \\
\text { Activity }\left(\mathrm{E}_{1}\right)\end{array}$ & 16 & 40 & 35.06 & 87.66 & 5.23 \\
\hline $\begin{array}{l}\text { After } \\
\text { Learning } \\
\text { Subjective } \\
\text { test }\left(\mathrm{E}_{2}\right)\end{array}$ & 16 & 60 & 46.94 & 78.23 & 6.11 \\
\hline Total & & 100 & 82.00 & 82.00 & $\mathbf{9 . 0 9}$ \\
\hline
\end{tabular}

- The percentage of sample students who scored the achievement on instructional activities on calculus for high school level by using a TI Nspire CX CAS graphing calculator of $70 \%$ or more of the total score and tested the number of students who qualified more than 60 percent of the total number of students as shown in table 2 .

TABLE II. PERCENTAGE OF SAMPLE STUDENTS WHO SCORED THE ACHIEVEMENT OF BASIC KNOWLEDGE ON INSTRUCTIONAL ACTIVITIES ON CALCULUS FOR HIGH SCHOLL LEVEL BY USING A TI NSPIRE CX CAS GRAPHING CALCULATOR OF 70\% OR MORE OF THE TOTAL SCORE AND TESTED THE NUMBER OF STUDENTS WHO QUALIFIED MORE THAN 60 PERCENT OF THE TOTAL NUMBER OF STUDENTS.

\begin{tabular}{|c|c|c|c|}
\hline $\begin{array}{c}\text { Total } \\
\text { Number } \\
\text { of } \\
\text { Students }\end{array}$ & $\begin{array}{c}\text { Number of students who scored } \\
\text { the achievement on instruction } \\
\text { activities on calculus for high } \\
\text { school level pass )Ratio( }\end{array}$ & $\begin{array}{c}\text { Test } \\
\text { Prep. }\end{array}$ & $\begin{array}{c}\text { Exact } \\
\text { Sig. } \\
\text { (1-tailed) }\end{array}$ \\
\hline 16 & $14(0.9)$ & 0.6 & $0.018^{*}$ \\
\hline
\end{tabular}

According to table 2, after instructional activities on calculus for high school level by using a TI Nspire CX CAS graphing calculator, the test results showed that students achieved the educational achievement of instructional activities on calculus for high school level by using a TI Nspire CX CAS graphing calculator, passing the criteria from $60 \%$ of the total number of students at a significant level of .05.

- The results of the analysis of students' satisfaction toward instructional activities on calculus for high 
school level by using a TI Nspire CX CAS graphing calculator are shown in table 3. According to table 3, students are satisfied with instructional activities on calculus for high school level by using a TI Nspire CX CAS graphing calculator as a whole with an average of 4.15 , which is very satisfied. When considering in an aspect, students are satisfied with instructional activities on calculus for high school level by using a TI Nspire CX CAS graphing calculator at the highest satisfaction level which was 7 . How much of the suitability of class and audiovisual equipment during the training workshop? 8 How much of the suitability of teaching material? However, students have a moderate level of satisfaction for 2. Before joining the training workshop, how much knowledge do you have toward instructional activities on calculus for high school level by using a TI Nspire CX CAS graphing calculator? While other aspects have a high level of satisfaction.

TABLE III. ARITHMETIC AVERAGES, THE STANDARD DEVIATION AND SATISFACTION LEVEL OF THE SAMPLE STUDENTS AFTER INSTRUCTIONAL ACTIVITIES ON CALCULUS FOR HIGH SCHOOL LEVEL BY USING A TI NSPIRE CX CAS GRAPHING CALCULATOR.

\begin{tabular}{|l|c|c|c|}
\hline \multicolumn{1}{|c|}{ Questions } & $\overline{\text { X }}$ & S.D. & $\begin{array}{l}\text { Satisfaction } \\
\text { level }\end{array}$ \\
\hline $\begin{array}{l}\text { 1. How much of the suitability of the time } \\
\text { frame and pattern of the training workshop? }\end{array}$ & 4.19 & 0.66 & High \\
\hline $\begin{array}{l}\text { 2. Before joining the training workshop, } \\
\text { how much knowledge do you have toward } \\
\text { instructional activities on calculus for high } \\
\text { school level by using a graphing calculator? }\end{array}$ & 3.06 & 0.99 & Moderate \\
\hline $\begin{array}{l}\text { 3. How much ability the lecturer have to } \\
\text { answer your question? }\end{array}$ & 4.25 & 0.58 & High \\
\hline $\begin{array}{l}\text { 4. To join a training workshop, make you } \\
\text { have ability and confidence. How much } \\
\text { ability do you have to share knowledge with } \\
\text { the lecturer? }\end{array}$ & 4.12 & 0.72 & High \\
\hline $\begin{array}{l}\text { 5. After joining the training workshop, how } \\
\text { many levels of knowledge do you have } \\
\text { toward instructional activities on calculus } \\
\text { for high school level by using a graphing } \\
\text { calculator? }\end{array}$ & 4.19 & 0.54 & High \\
\hline $\begin{array}{l}\text { 6. Do you think you can apply the } \\
\text { knowledge that you got from the lecturer for } \\
\text { yourself? }\end{array}$ & 4.44 & 0.63 & High \\
\hline $\begin{array}{l}\text { 7. How much of the suitability of class and } \\
\text { audiovisual equipment during the training } \\
\text { workshop? }\end{array}$ & 4.31 & 0.79 & Highest \\
\hline $\begin{array}{l}\text { 8. How much of the suitability of teaching } \\
\text { material? }\end{array}$ & 4.38 & 0.50 & Highest \\
\hline $\begin{array}{l}\text { 9. How much satisfaction do you have from } \\
\text { the overall training workshop? }\end{array}$ & 4.19 & 0.66 & High \\
\hline $\begin{array}{l}\text { 10. Do you think the training workshop } \\
\text { should be held in the future? }\end{array}$ & 4.38 & 0.50 & High \\
\hline Total & 4.15 & 0.50 & High \\
\hline
\end{tabular}

\section{SUMMARY OF RESUlTS, DiscuSS THE FINDINGS AND SUGGESTIONS}

\section{A. Summary of Results}

- Students had achievement toward instructional activities on calculus for high school level by using a TI Nspire
CX CAS graphing calculator passing the criteria from $60 \%$ of the total number of students at a significant level of .05.

- Instructional activities on calculus for high school level by using a TI Nspire CX CAS graphing calculator had performance value equal to $87.66 / 78.23$ which was effective according to criteria $75 / 75$ that was set.

- Students were satisfied with instructional activities on calculus for high school level by using a TI Nspire CX CAS graphing calculator as a whole with an average of 4.15 , which was very satisfied.

\section{B. Discuss the Findings}

The results can be discussed as follows:

1. According to the study, more than 60 percent of all students have the ability for instructional activities on calculus for high school level by using a TI Nspire CX CAS graphing calculator. The instructor arranges the content and activities from basic to more advance and reviews the basic knowledge that the students have studied. The instructor explains steps in detail by using a TI Nspire CX CAS graphing calculator for learning calculus for the high school level. Students have a chance to practice on their own. They are eager to study and don't feel tired of studying and doing activities. All learners focus on the graphing calculator monitor or focus on the large screen in front of the class showing the instructor's graphing calculator monitor. This allows students to concentrate on the subject and the skills of using a graphing calculator on calculus for the high school level. This enables students to learn nonstudied content and have better graphing calculator skills than in the early stages of teaching.

Examples of commands, limit of function, and area between two curves used in TI Nspire CX CAS graphing calculators of Instructional activities on calculus for high school level by using a TI Nspire CX CAS graphing calculator were shown in Figure 1, 2, and 3 respectively.

2. The results of the development and effectiveness of Instructional activities on calculus for high school level by using a TI Nspire CX CAS graphing calculator showed that Instructional activities on calculus for high school level by using a TI Nspire CX CAS graphing calculator created by the researchers was as effective as 87.66/78.23, with a threshold of $75 / 75$, when considering an inter-study score (E1) above the 75 threshold set, as the researchers conducted the process of Instructional activities on calculus for high school level by using a TI Nspire CX CAS graphing calculator by exploring the structure of the content, dividing the course content. Create activities that use a TI Nspire CX CAS graphing calculator in detail. Researchers provide class material and students can act on their own, and post-school test scores (E2) are not much higher than the 75 threshold set because students have limited time to review content and activities using graphing calculators. 
3. Students who attend training workshop are satisfied with Instructional activities on calculus for high school level by using a TI Nspire CX CAS graphing calculator at a high level as a whole which may come from the content of Instructional activities on calculus for high school level by using a TI Nspire CX CAS graphing calculator. Students can apply the content for their research and the lecturer can also convey the content and develop activities on Instructional activities on calculus for high school level by using a TI Nspire CX CAS graphing calculator. The lecturer conveyed the content with TI Nspire CX CAS graphing calculator to help for calculation, students have a chance to attend a workshop at the Department of Mathematics, Faculty of Sciences, Srinakharinwirot University for 2 days. There is one TI Nspire CX CAS graphing calculator equipment per person.

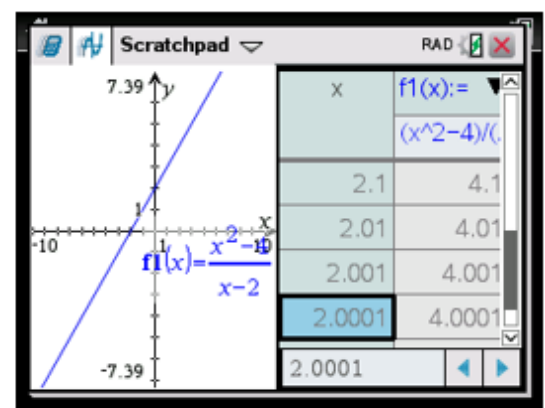

Plot graph and show the table

\begin{tabular}{|c|c|}
\hline \multirow{2}{*}{\multicolumn{2}{|c|}{$\begin{array}{l}\text { Ix } 1: \text { Actions } \\
\frac{1}{3} \times 5 \text { 2: Number }\end{array}$}} \\
\hline & \\
\hline$x=3:$ Algebra & 2: Factor \\
\hline$f(x)$ : Calculus & 3: Expand \\
\hline 5: Probability & 4: Zeros \\
\hline X 6: Statistics & 5: Complete the Square \\
\hline$[$ [맘] 7: Matrix \& V & 6: Numerical Solve \\
\hline$\$ \in 8:$ Finance & 7: Solve System of Equations \\
\hline 雷 9: Functions & 8: Polynomial Tools \\
\hline & A: Convert Expression \\
\hline
\end{tabular}

Command for basic Algebra

\begin{tabular}{|c|c|}
\hline \\
\hline \multicolumn{2}{|c|}{ 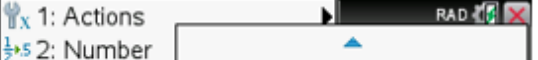 } \\
\hline \multirow{7}{*}{ 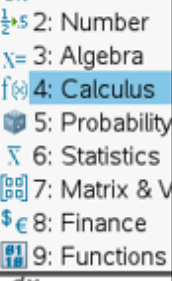 } & 6: Product \\
\hline & 7: Function Minimum \\
\hline & 8: Function Maximum \\
\hline & 9: Tangent Line \\
\hline & A: Normal Line \\
\hline & B: Arc Length \\
\hline & C:Series \\
\hline \multirow[t]{3}{*}{$d x$} & D:Differential Equation Solver \\
\hline & E: Implicit Differentiation \\
\hline & F: Numerical Calculations \\
\hline
\end{tabular}

Finding implicit function derivatives.

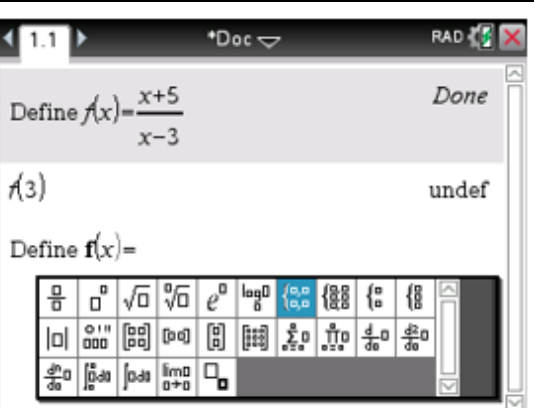

Step function

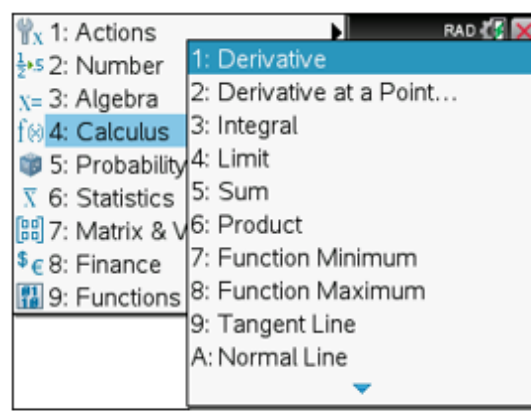

Command for Calculus

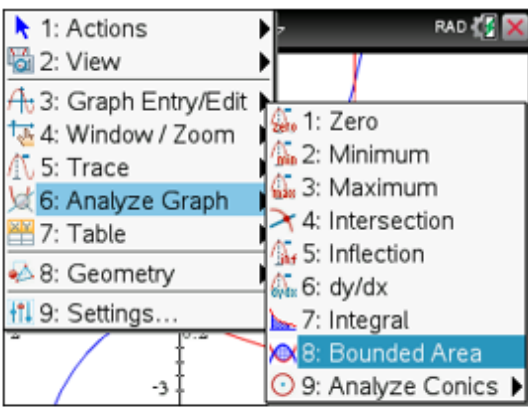

Finding an area in an enclosed area.

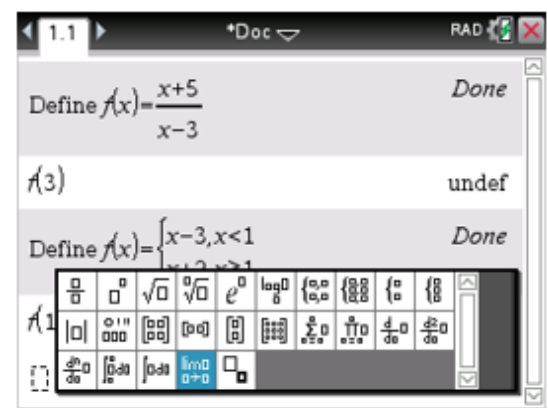

Buttons for mathematical calculations

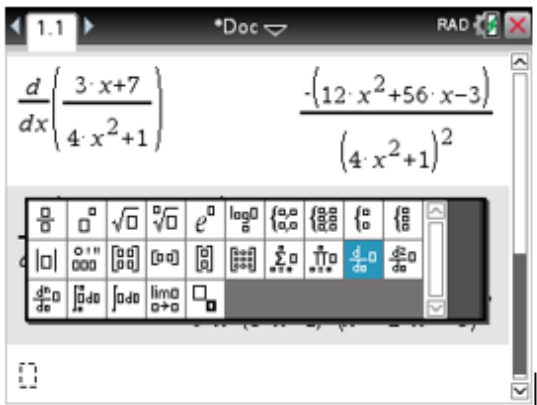

Examples of finding function derivatives

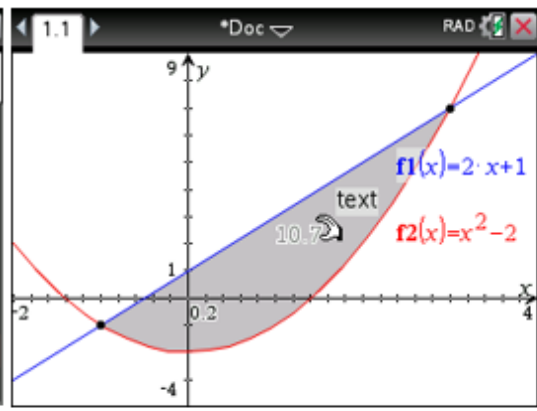

Finding area between curves.

Fig. 1. Example of commands used in TI Nspire CX CAS graphing calculators 


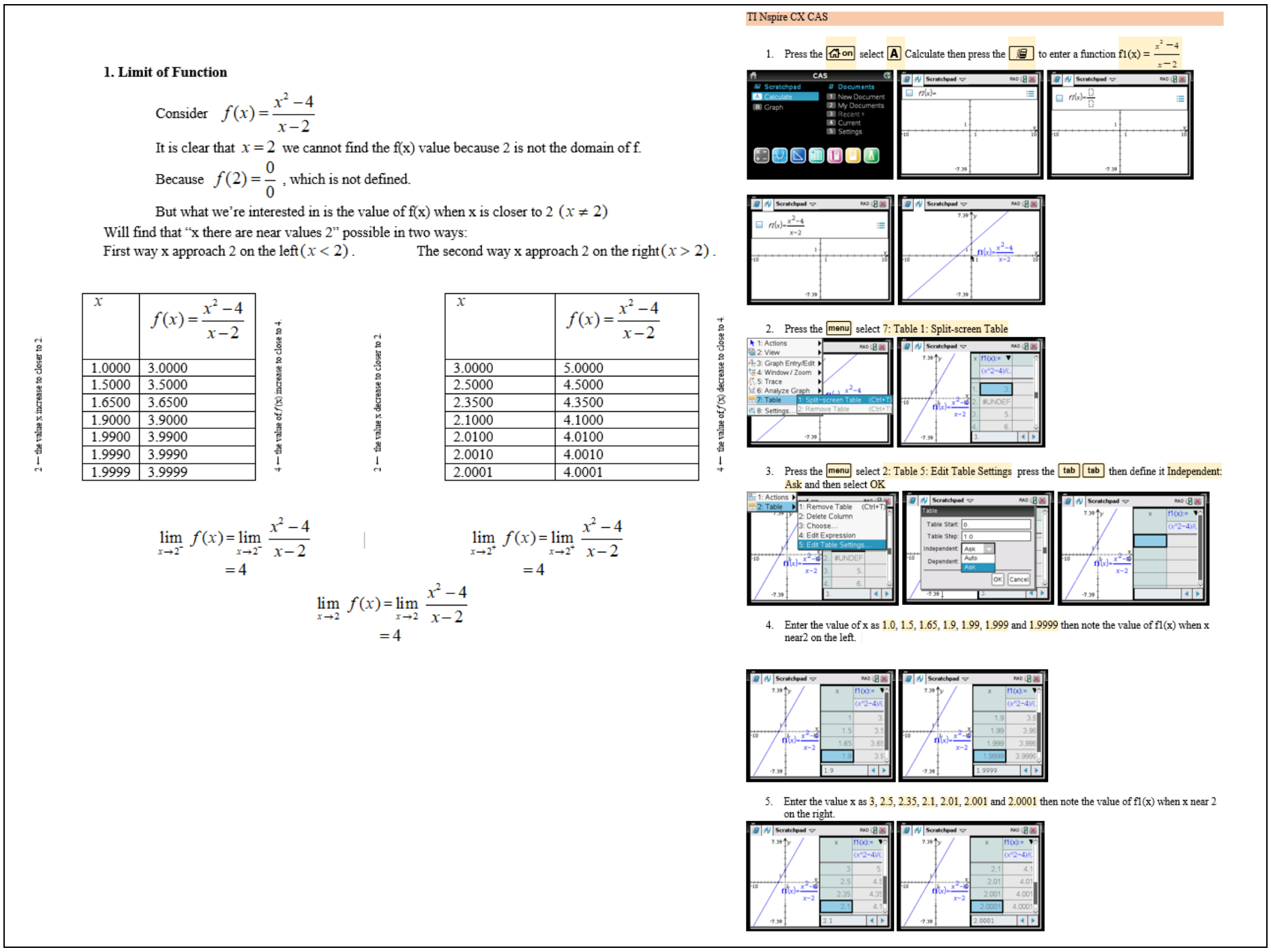

Fig. 2. Example of limit of function used in TI Nspire CX CAS graphing calculators 


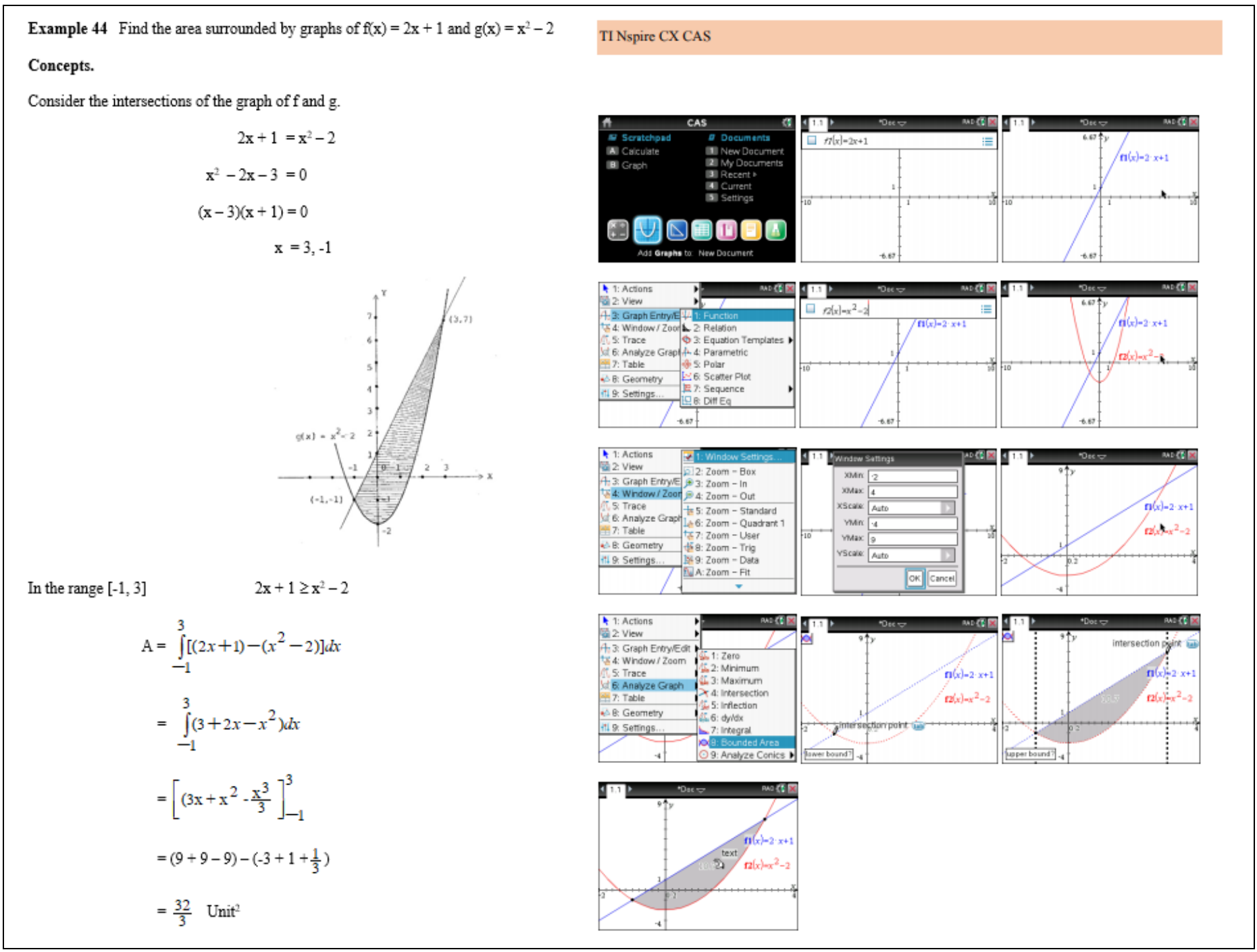

Fig. 3. Example of area between two curves used in TI Nspire CX CAS graphing calculators

\section{CONCLUSION AND SUGGESTIONS}

\section{A. Conclusion}

The result of the study indicated that students had educational efficiency to pass the criteria more than 60 percent of the total students with a statistical significance level of .05. The effectiveness (efficiency of process $\left(E_{1}\right)$ /efficiency of product $\left(\mathrm{E}_{2}\right)$ ) of the instructional activities on calculus for high school level by using a TI Nspire CX CAS graphing calculator equal to $87.65 / 78.23$. The students' satisfaction toward instructional activities on calculus for high school level by using a TI Nspire CX CAS graphing calculator was at a high level.

\section{B. Suggestions}

1) Recommendations to implement the findings: The results indicate that Instructional activities on calculus for high school level by using a TI Nspire CX CAS graphing calculator can improve the calculus ability of the high school level for sample students. Therefore, there are important suggestions as follows:

- Students who attend Instructional activities on calculus for high school level by using a TI Nspire CX CAS graphing calculator should have preliminary knowledge of the using a TI Nspire CX CAS graphing calculator.

- Instructional activities on calculus for high school level by using a TI Nspire CX CAS graphing calculator, instructors should allow learners to learn definitions and/or process of solving without using graphing 
calculators first. Once the learner understands, the graphing calculator will only be introduced to help students to make calculations faster. But the process of solving the problem, graphing calculators can't create their troubleshooting process. Learners will only enter a command for graphing calculators to process. The learner does not lose the concept of problem-solving.

\section{2) Suggestions for future research}

- There should be a study on the effects of using graphing calculators for calculus teaching at the high school level, by adding more practical training and spend time teaching at normal times or inserting in the contents of one of the courses.

- There should be a study on the effects of using graphing calculators for calculus teaching at the high school level with high school students in the form of classroom research or future research.

\section{ACKNOWLEDGMENT}

The empirical research for this study was funded by a grant from Faulty of Sciences, Srinakharinwirot University. Thank you so much for all Department of Mathematics for your supports including equipment's, places, and facilities.

\section{REFERENCES}

[1] N. Kamol, Effects of using graphic calculator on mathematics concept and spatial ability of MATHAYOM SUKSA three students in the demonstration schools under the ministry of university affairs. Degree of Master of Education in Mathematics Educations, Chulalongkorn University Bangkok, 1999.
[2] S. Plangprasopchok, "The practice set creation of calculus II for mathematics students in Phranakhon Rajabhat University," Rhranakhon Rajabhat Research Journal, vol. 10, no. 2, 2015.

[3] C. Beth, "Teaching Calculus with Graphing Calculators," Retrieved November 23, 2007, from http://curry.edschool.virginia.edu/ciass/edlf/ 589/reviews/graping_calcs.dog, 2001.

[4] Ng Wee Leng, "Using an advanced graphing calculator in the teaching and learning of calculus International," Journal of Mathematical Education in Science and Technology, vol. 42, no. 7, pp. 925-938, 2011.

[5] P. Tassanametee, and S. Sotaro, "Instructional activity package on matrices by using graphic calculator for Matayomsuksa four students," Srinakharinwirot Science Journal, vol 34, no. 1, pp. 247-262, 2018

[6] S. Sotaro, K. Panichakarn, and R. Ngamsuntikul, "Instructional activity on statistics in high school by using graphing calculator TI Nspire CX CAS," Thaksin University Journal, vol. 21, no. 3, pp. 233-240, 2018.

[7] S. Sotaro, R. Ngamsuntikul, and K. Panichakarn, "Instructional activity on statistics for research by using graphing calculator TI Nspire CX CAS," Proceedings of the 10th National Science Research Conference $24^{\text {th }}-25^{\text {th }}$ May 2018, Mahasarakham University, pp. 1104-1114, 2018

[8] W. Chamnan, and S. Sotaro, "Instructional activity package an linear programming using a graphic calculator for Mathayomsuksa five students," Journal of Industrial Education, vol. 17, no 2, pp. 134-142, 2018.

[9] K. Tiengyoo, and S. Sotaro, "Instructional activity package an relations and functions by using a graphing calculator for Mathayomsuksa students," Journal of Industrial Education, vol. 17, no. 2, pp. 143-150, 2018.

[10] T. Wises, and S. Sotaro, "Instructional activity package on conic sections by using a TI-Nspire CX CAS Graphing Calculator for Matthakom 4 students," Journal of Industrial Education, vol. 18, no. 2, pp. 148-155, 2019.

[11] S. Sotaro, S. Thaithae, and P. S. Sirininlakul, "Instructional activity on Pre-calculus by using graphing calculator TI Nspire CX CAS," Proceedings of the 11 National Science Research Conference $23^{\text {rd }}-24^{\text {th }}$ May 2019, Srinakharinwirot University, pp. 1031-1039, 2019.

[12] P. Kannasoot, Statistics for the Behavioral Science Research. Bangkok. Chulalongkorn University, 1995. 